\title{
Exploring self-leadership development among Malaysian women entrepreneurs
}

\begin{abstract}
The Problem: In Malaysia, women entrepreneurs are underrepresented, and little is known about their development of self-leadership. Official statistics indicate that approximately half of the businesses run by women remain underperforming. This shows that women entrepreneurs' selfleadership is an issue that should be addressed. The Solution: This study aims to explore selfleadership development of Malaysian women entrepreneurs. Qualitative interviews with seven women entrepreneurs were conducted. The study findings indicated that self-leadership is a process that can be developed and mastered by women entrepreneurs so that they have better chances of success in their business start-ups. This study provides a model of the self-leadership process that illustrates a range of influences that are likely to contribute to women entrepreneurs' self-leadership development. The Stakeholders: The model developed would be beneficial to human resource development (HRD) practitioners and Malaysian government agencies (e.g., SME Corporation Malaysia) that design and deliver interventions (e.g., incubator programs and training workshops) focusing on women entrepreneurs' self-leadership development.
\end{abstract}

Keyword: Women entrepreneurs; Self-leadership development; Malaysia 